\title{
First Report of Gray Mold Disease (Botrytis cinerea Pers. Fr.) on Capsicum (Capsicum annuum var. grossum) from Jammu \& Kashmir
}

\author{
Taibah Bashir*, Ali Anwar, Rabia Latif, Rovidha S. Rasool and Aqleema Bano \\ Division of Plant Pathology, Sher-e- Kashmir University of Agricultural Sciences and \\ Technology of Kashmir, Shalimar Campus, Srinagar 190025, India \\ *Corresponding author
}

\begin{abstract}
A B S T R A C T
Keywords

Gray mold disease, Capsicum, Botrytis cinerea, Economic loss

Article Info

Accepted:

05 February 2020

Available Online:

10 March 2020

The gray mold disease of capsicum (Capsicum annum var. grossum) caused by Botrytis cinerea Pers. is one of the major destructive fungal disease of bell pepper in Kashmir. The disease symptoms appeared on leaves and fruits of capsicum plant and were prevalent from July to September, causing economic loss to the crop. This disease was first time reported from Kashmir valley. The fungus was isolated on Potato Dextrose Agar from the diseased samples and incubated at $25 \pm 2^{0}$. Based on pathogenecity, symptomatology and morpho-cultural characteristics, the pathogen was identified as Botrytis cinerea.

\section{Introduction}

Bell pepper (Capsicum annuum L.) popularly known as sweet pepper or Shimla mirch, a member of Solanaceae family, is an important vegetable crop grown worldwide for its delicate taste, pleasant flavour and colour. The nutritional value of hot pepper merits special attention, because it is a rich source of vitamin $A, C, E$ and a good source of $B_{2}$, potassium, phosphorus and calcium. Despite appreciable quantities of ascorbic acid, provitamin A ( $\beta$-carotene) and other carotenoid pigments such as lycopene and zeaxanthin are also present which are beneficial for prevention of cancer and

cardiovascular human diseases

(Ghasemnezhad et al., 2011). In Kashmir, during favourable environmental conditions especially during high precipitation the crop is attacked from its early to maturity stage by this unreported disease resulting in severe leaf spotting, fruit rotting and pre-mature withering of the plant which is a major constraint in its successful cultivation. The aim of the present study was to identify the disease and the associated causal pathogen. Leaf infection begins as small irregularly brown colored spots that later colease and turn into white to gray centered lesions with brown margins (Plate-1). On fruit initial symptoms appeared as small light yellowish-
\end{abstract}


brown lesions that later increased in size rapidly and developed a soft watery decay on the surface of infected fruit. Internal symptoms included gray mycelial growth with abundant conidia and rotting lesions on the fruits (Plate-2).

Botrytis cinerea is an unspecialized necrotrophic fungus that produces grayish mass of mycelium, conidiophores, and conidia on the surface of rotted tissues. On Potato dextrose agar medium, the fungal culture exhibited cottony growth with aerial mycelium. Initially the colonies were white which later turned grayish white and then finally grayish in color after formation of conidia and conidiophores at 15 days of incubation (Plate-3). Microscopic examination of the fungus revealed that the hyphae was branched, septate and hyaline in colour and measured 7.1-14.5 $\mu \mathrm{m}$ in width. Black, hard, round to irregular sclerotia were formed after 7-10 days of incubation and measured $2.0-6.5 \times 1.8$ to $5.0 \mathrm{~mm}$ (Plate 4). The conidiophores born directly on hyphae were straight, irregularly branched near the apex and hyaline in colour measuring 14.5$16.5 \times 27.0-30.5 \mu \mathrm{m}$ (Plate-5). The conidia produced on branched conidiophores were single celled, ellipsoid to obovoid in shape, and have a smooth surface and hyaline in

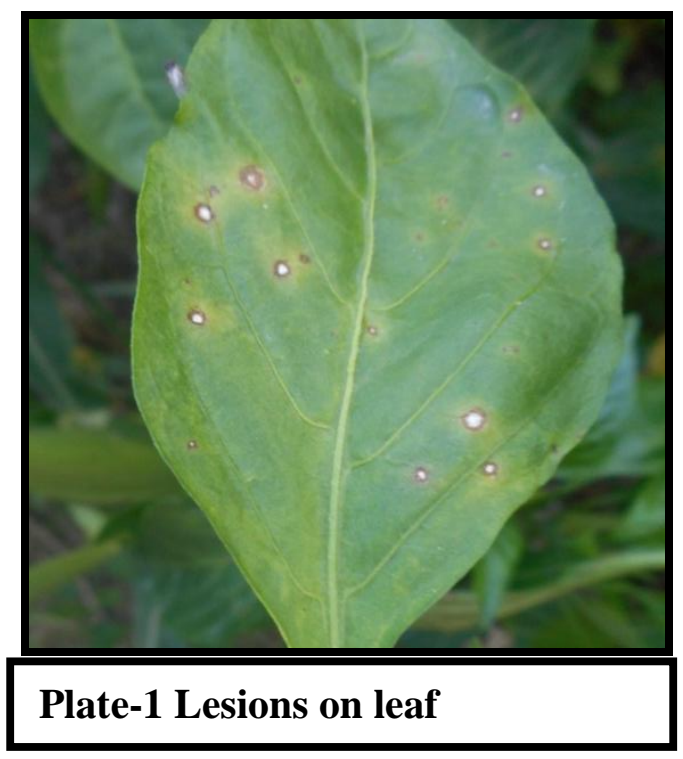

colour measuring 8-14 x 6-9 $\mu \mathrm{m}$ (Plate-6). On host, the causal fungus produced septate mycelium measuring 6.7-13.5 $\mu \mathrm{m}$ in width and a long, apically branched conidiophores measuring 12.5-15.0 x25.5-30.0 $\mu \mathrm{m}$ which produced ovoid and unicellular conidia measuring 6.0-12.0x 4.0-7.0 $\mu \mathrm{m}$. Black elliptical sclerotial bodies were also observed on rotted fruits, measuring 1.5-4.0x 1.5-3.0 $\mathrm{mm}$. The Pathogenicity test of the isolated fungus was performed by following Koch's postulates. On the basis of symptomatology, pathogenecity and morphological characteristics, the fungus was identified as Botrytis cinerea Pers. Fr.

Botrytis cinerea causing gray mold disease is well known for its worldwide distribution and extensive host range of more than 100 plant species from different genera including vegetables, ornamental plants, field and glasshouse crops, fruits and post-harvest produce (Sun et al., 2017). The disease is known to occur on chickpea, strawberry, grapevine, apple, carrot, castor, tomato, pea, pepper, chrysanthemum, lily, rose, gladiolus, and tulip (Chand 1997, Kurbetli et al., 2016). However, to our knowledge, this is the first report of $B$. cinerea causing gray mold disease on bell pepper from Jammu \& Kashmir.

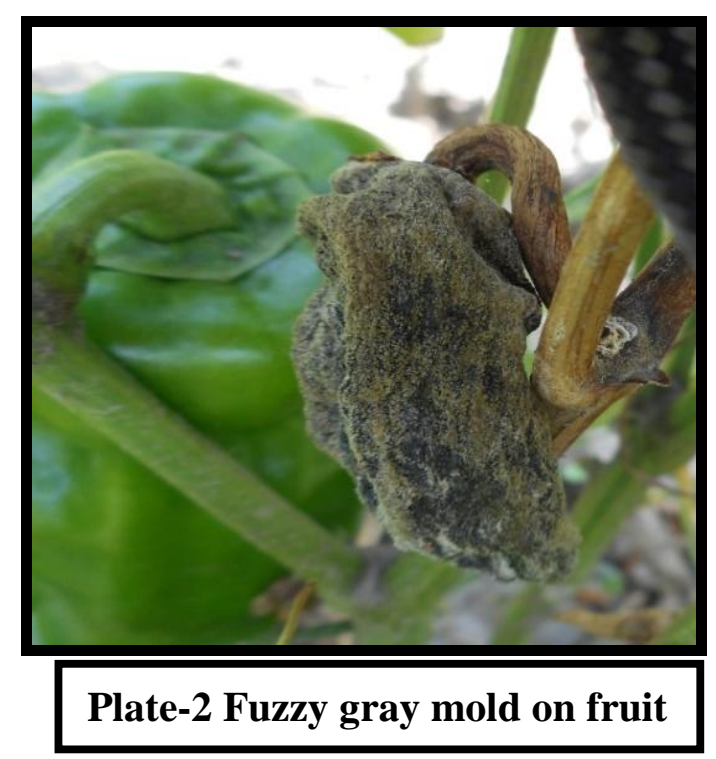




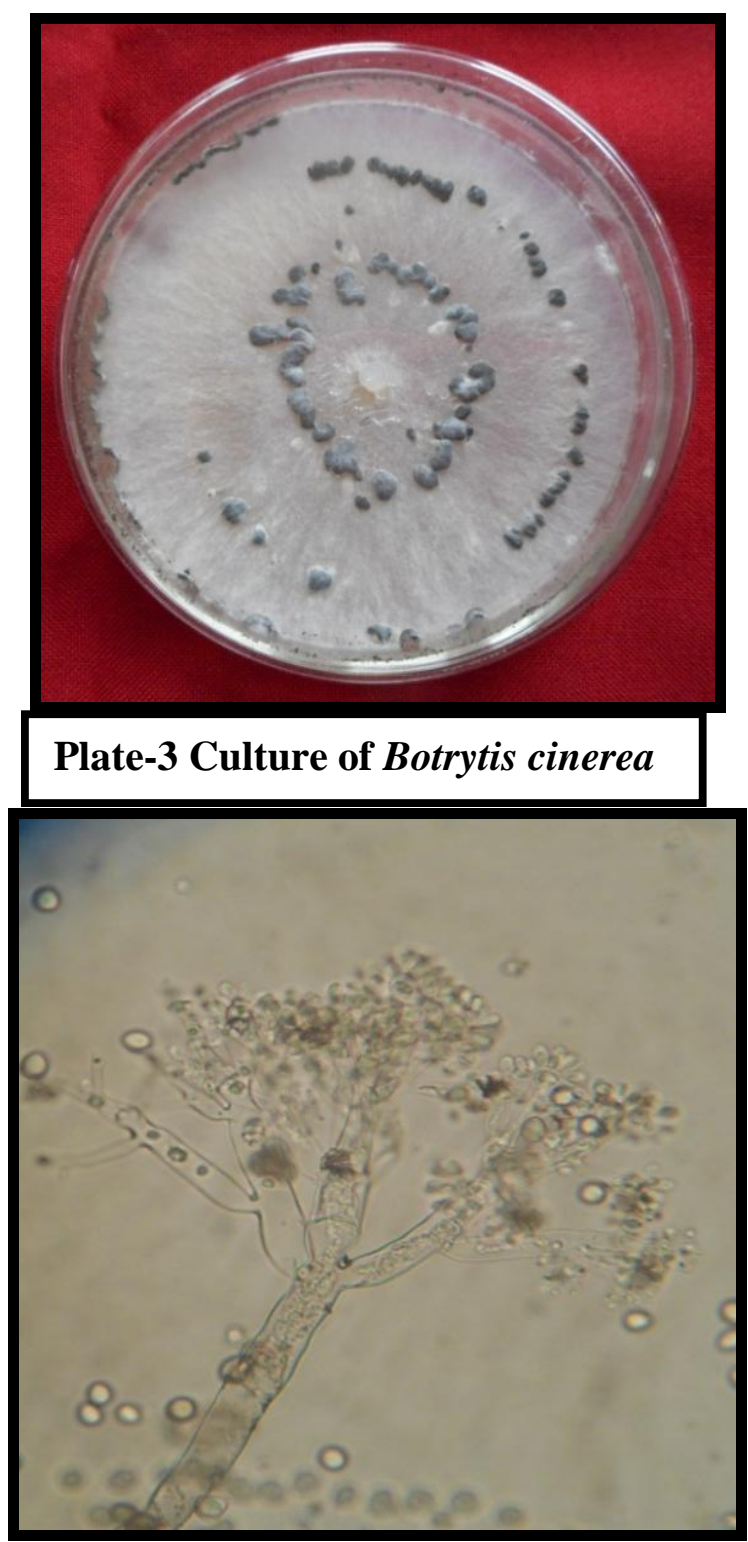

Plate-5 Conidiophore bearing conidia

\section{References}

Chand. H. 1997. Botrytis grey mould of chickpea (Cicer arietinum L.) in India - a review. Agricultural Review 18, 43-48.

Ghasemnezhad, M., Sherafati, M. and Payvas, G.A. 2011. Variation in phenolic compounds, ascorbic acid and antioxidant activity of five coloured bell pepper(Capsicum annuиm L.) fruits at two different harvest times. Journal of
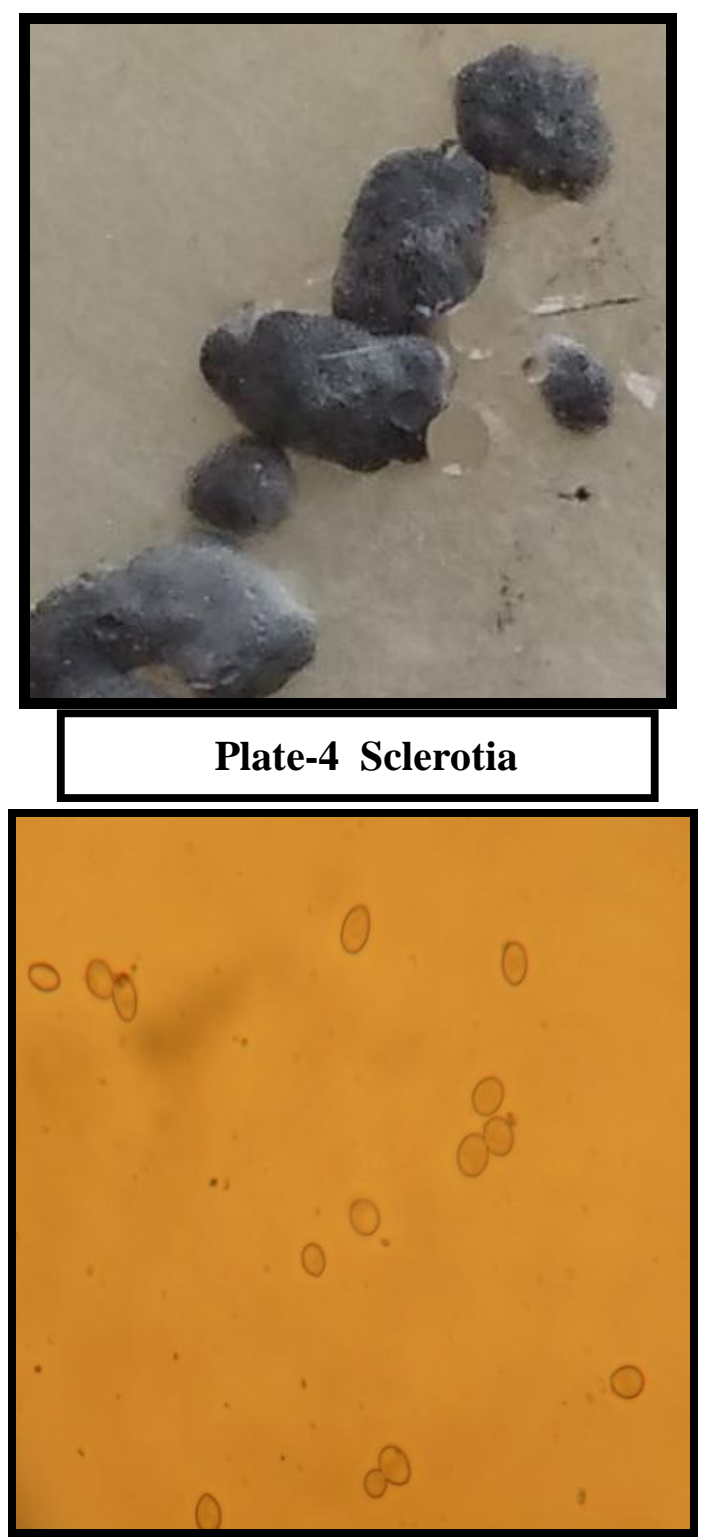

Plate-6 Conidia

Functional Foods 3: 44-49.

Kurbetli, I., Aydogdu, M., Sulu, G. and Polat, I.2016. First report of pre-harvest rot of pear fruit caused by Botrytis cinerea in Turkey. New Disease Reports 34: 16

Sun, G.Z., Wang, H., Shi, B.B., Shangguan, N.N. and Wang, Y., Ma, Q. 2017. Control efficiency and expressions of resistance genes in tomato plants treated with $\varepsilon$-poly-llysine against Botrytis cinerea. Pestic. Biochem. Phys. 143, 191-198. 


\section{How to cite this article:}

Taibah Bashir, Ali Anwar, Rabia Latif, Rovidha S. Rasool and Aqleema Bano. 2020. First Report of Gray Mold Disease (Botrytis cinerea Pers. Fr.) on Capsicum (Capsicum annuum var. grossum) from Jammu \& Kashmir. Int.J.Curr.Microbiol.App.Sci. 9(03): 922-925. doi: https://doi.org/10.20546/ijcmas.2020.903.108 